\title{
Multi-Level Operation with Two-Level Converters through a Double-Delta Source Connected Transformer
}

\author{
Yongsoon Park ${ }^{*}$, Sungjae $\mathrm{Ohn}^{*}$, and Seung-Ki Sul ${ }^{\dagger}$ \\ ${ }^{*}$ Department of Electrical and Computer Engineering, Seoul National University, Seoul, Korea
}

\begin{abstract}
This paper proposes a power conversion topology involving a multi-winding transformer and converters. The fundamental idea is described with circuit diagrams, and the voltage output of the proposed topology is analyzed mathematically. The effectiveness of the topology is discussed with test results from a small-scale power conversion system. When conventional hardware consisting of two-level converters and a transformer is employed, multi-level voltage outputs can be applied to the transformer windings by the proposed method.
\end{abstract}

Key words: Converter, Multi-level, Multi-winding, Transformer

\section{INTRODUCTION}

Energy storage system (ESS) is getting attention in grid applications. ESS can be diversely utilized in transmission or distribution grids for frequency regulation, spinning reserve, peak shaving, and so on [1]. In addition, ESS can be integrated with renewable energy resources such as wind and solar energy to compensate for the volatility [2], [3]. Although ESS has great potential in terms of functionality, its feasibility should be discussed with a consideration of cost-effectiveness.

The regulation service is deemed to be advantageous for ESS even in costs by virtue of its fast response [4]. This regulation service is supposed to be continued for less than an hour at a time [4], [5]. Among various energy storage sources, lithium-ion battery can be the best choice for this type of application [6]. In particular, ESS using battery is referred to as battery ESS (BESS).

The converter is essential for the grid connection of BESS because power conversion between $\mathrm{DC}$ and $\mathrm{AC}$ is required. In general, a passive filter is used to attenuate the current ripples caused by pulse-width modulation (PWM) [7], [8]. Since this type of passive filter is bulky, it is desirable to reduce its size to

Manuscript received Jun. 17, 2014; accepted Sep. 30, 2014

Recommended for publication by Associate Editor Dong-Choon Lee.

${ }^{\dagger}$ Corresponding Author: sulsk@plaza.snu.ac.kr

Tel: +82-2-880-7243, Fax: +82-2-878-1452, Seoul Nat'l University

*Dept. of Electrical and Computer Eng., Seoul Nat'l University, Korea save manufacturing and installation costs. One simple way to achieve size reduction is to increase the switching frequency of the converter given that the inductive impedance becomes large at high frequency. However, higher switching frequency means larger switching loss, which is unfavorable for large-scale power conversion systems (PCSs).

This study has arisen from an desire to eliminate the additional passive filter. Initially, the following fact was focused on: transformer and parallel operation are inevitable in large-scale PCSs for practical reasons. Namely, a step-up transformer is required to increase transmission efficiency, and several converters have to be operated in parallel due to the limited current rating of existing semiconductor switches. If the carriers of parallel converters are interleaved [9], and the output currents per each phase are magnetically coupled through the transformer, the phase-shifted ripples would be cancelled out at the primary side of the transformer while no circulation current flows among the converters due to galvanic isolation. This conventional method seems to be a plausible approach for eliminating the additional filters.

This study has been developed with the aim of increasing the power conversion efficiency in addition to the filter elimination. This improvement can be simply achieved by modifying the wiring among the transformer and converters. Multi-level voltage waveforms appear on each of the transformer winding even though two-level converters are connected. By this modification, the voltage ripples near the switching frequency 
can be reduced by half. As a result, the current ripples in each of the converters can be reduced. This gives rise to reductions in the semiconductor loss and in the associated loss of the transformer itself. The proposed method is described in detail and compared to the conventional one.

\section{DOUBLE Delta SOURCED TRANSFORMER (DDST)}

\section{A. Circuit Diagrams}

Initially, the proposed method is discussed in comparison with the conventional method in terms of their circuit diagrams. Fig. 1 shows a multi-winding transformer connected to converters in the conventional way to minimize the passive filter. In this figure, two converters are participating in power conversion. As an example of the transformer winding, the voltages induced on $\alpha_{1}$ and $\alpha_{2}$ are in phase with that of $\alpha_{\mathrm{p}}$. The voltage magnitudes of $\alpha_{1}$ and $\alpha_{2}$ are determined by that of $\alpha_{p}$ and the turn ratio. As shown in Fig. 1, the abc-converter is electrically separated from the rst-converter. In addition, these converters are magnetically coupled to each other via the transformer's core.

On the other hand, Fig. 2 shows the proposed wiring method. Compared to the conventional method where the converters are electrically isolated, there are electrical connections by which the converter outputs are combined. In detail, if one terminal of the secondary winding is connected to the abc-converter, the other must be connected to the rst-converter. This point is further definite in Fig. 3 where only the secondary windings are considered without the primary side. Because the line-to-line voltages from each of the converters are applied to the windings, the converters' outputs are equivalently presented as delta voltage sources. This configuration has been named the Double Delta Sourced Transformer (DDST).

In the DDST, each of the secondary windings can be electrically affected by both of the converters. For instance, one turn-on/off in the abc-converter can change the voltages applied on the $\alpha_{1} \beta_{1} \gamma_{1}$ and $\alpha_{2} \beta_{2} \gamma_{2}$ windings simultaneously. Therefore, in the DDST, carrier interleaving can be utilized to minimize the current ripple of the secondary windings as well as that of the primary windings.

\section{B. Voltage on Each of the Windings by Three-Phase Sinusoidal Sources}

The three-phase voltages from the converters are the main factor in regulating the power transfer between the DC sources and the AC grid. Namely, the active/reactive powers can be modulated by adjusting the phase and magnitude of those voltages at the fundamental frequency.

The voltages on each of the windings can be derived according to the superposition principle. By this principle, all of the independent sources have to be deactivated except for the one under consideration. When it comes to the

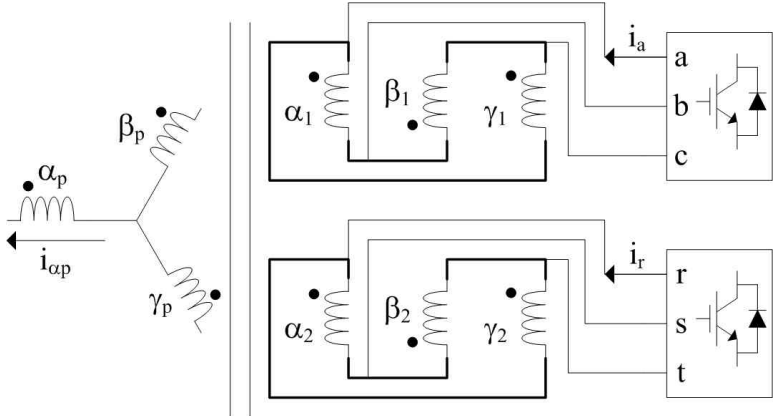

Fig. 1. Conventional connection among multi-winding transformer and converters without passive filter.

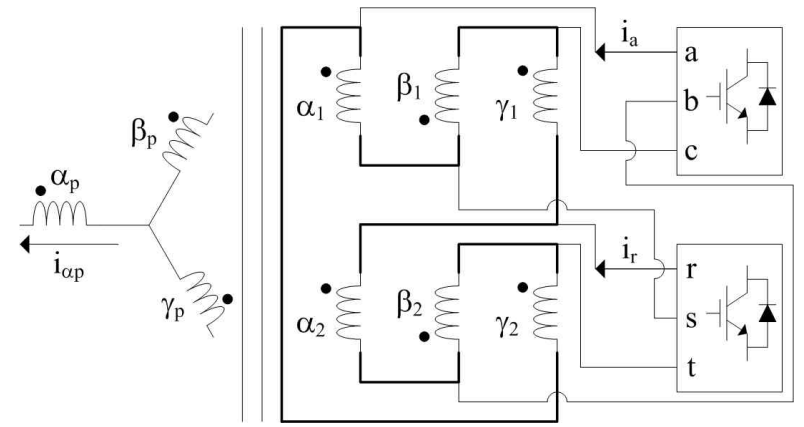

Fig. 2. Proposed connection among multi-winding transformer and converters without passive filter.

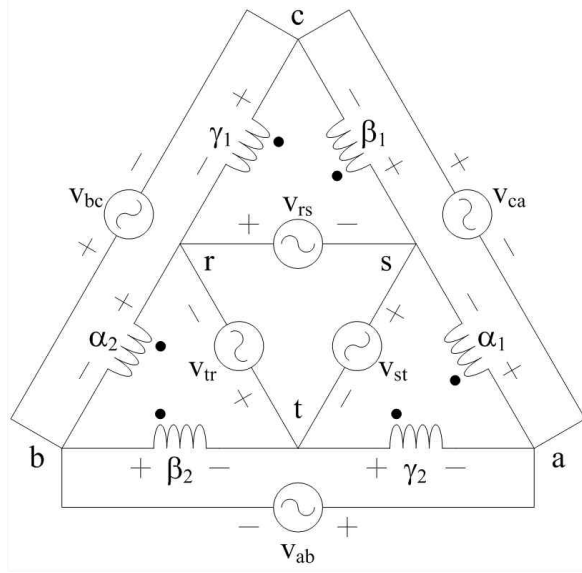

Fig. 3. Proposed connection when considering the secondary windings only.

single-phase, there seems to be six independent sources in Fig. 3 . However, one three-phase voltage means one set of three dependent voltages because their magnitude is the same, and their phase is shifted by $120^{\circ}$ with respect to each other.

One three-phase voltage source has to be regarded as one independent source to be deactivated. Then, the effects of abc-converter to the windings can be examined as shown in Fig. 4. The circuit in Fig. 4 can be equivalently drawn as Fig. 5 to aid in understanding. Namely, the delta voltage source is transformed into a wye voltage source. Similarly, the effects of the rst-converter to the windings can be considered as shown in Fig. 6, by deactivating the abc-converter.

Then, by superposing each deactivation result, the winding 


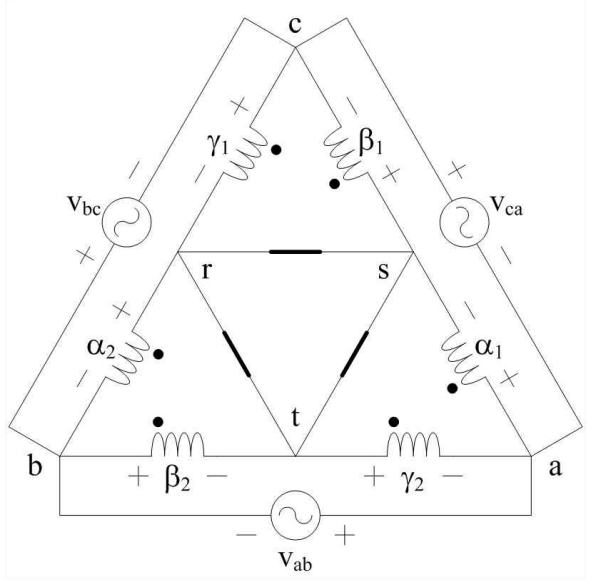

Fig. 4. Deactivation of rst-source.

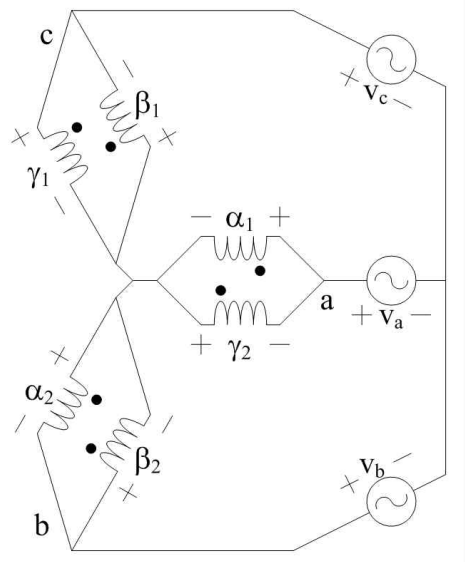

Fig. 5. Deactivation of rst-source: equivalent circuit.

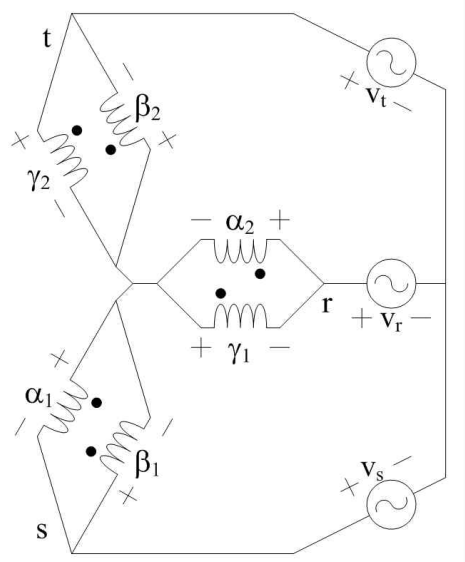

Fig. 6. Deactivation of abc-source: equivalent circuit.

voltages can be derived from Figs. 5 and 6 as:

$$
\begin{aligned}
& \left\{\begin{array}{l}
\mathrm{v}_{\alpha 1}=\mathrm{v}_{\mathrm{a}}-\mathrm{v}_{\mathrm{s}} \\
\mathrm{v}_{\beta 1}=-\mathrm{v}_{\mathrm{c}}+\mathrm{v}_{\mathrm{s}} \\
\mathrm{v}_{\gamma 1}=\mathrm{v}_{\mathrm{c}}-\mathrm{v}_{\mathrm{r}}
\end{array}\right. \\
& \left\{\begin{array}{l}
\mathrm{v}_{\alpha 2}=-\mathrm{v}_{\mathrm{b}}+\mathrm{v}_{\mathrm{r}} \\
\mathrm{v}_{\beta 2}=\mathrm{v}_{\mathrm{b}}-\mathrm{v}_{\mathrm{t}} \\
\mathrm{v}_{\gamma 2}=-\mathrm{v}_{\mathrm{a}}+\mathrm{v}_{\mathrm{t}}
\end{array} .\right.
\end{aligned}
$$

When the phase voltages generated by the converters are given as (2), the winding voltages are derived as (3) from (1). The voltages in (2) and (3) are expressed with the phasor.

$$
\begin{aligned}
& \left\{\begin{array}{l}
\mathrm{v}_{\mathrm{a}}=\mathrm{v}_{\mathrm{r}}=\mathrm{V}_{\mathrm{m}} \angle 0^{\circ} \\
\mathrm{v}_{\mathrm{b}}=\mathrm{v}_{\mathrm{s}}=\mathrm{V}_{\mathrm{m}} \angle-120^{\circ} \\
\mathrm{v}_{\mathrm{c}}=\mathrm{v}_{\mathrm{t}}=\mathrm{V}_{\mathrm{m}} \angle+120^{\circ}
\end{array}\right. \\
& \left\{\begin{array}{l}
\mathrm{v}_{\alpha 1}=\mathrm{v}_{\alpha 2}=\sqrt{3} \mathrm{~V}_{\mathrm{m}} \angle 30^{\circ} \\
\mathrm{v}_{\beta 1}=\mathrm{v}_{\beta 2}=\sqrt{3} \mathrm{~V}_{\mathrm{m}} \angle-90^{\circ} . \\
\mathrm{v}_{\gamma 1}=\mathrm{v}_{\gamma 2}=\sqrt{3} \mathrm{~V}_{\mathrm{m}} \angle 150^{\circ}
\end{array}\right.
\end{aligned}
$$

When considering the magnitude and phase in (3), the voltages applied to the windings in the DDST do not differ from the line-to-line voltages directly available from a single converter in the conventional way. That is, in terms of the modulation index, the proposed system can handle the same range of power transfer as the conventional one at the fundamental frequency.

When there is a converter fault in the DDST, the equivalent circuit can be derived as shown in Fig. 7. When one converter ( $\mathrm{rst}$ ) is tripped, the remaining converter ( $\mathrm{abc}$ ) has to interact with the winding voltages of $v_{\beta 2}+v_{\gamma 2}, v_{\gamma 1}+v_{\alpha 2}$, and $v_{\alpha 1}+v_{\beta 1}$. For example, when no currents flow in the windings, these voltages have the same magnitude as $\mathrm{v}_{\alpha 1}$, $\mathrm{v}_{\beta 1}$, or $\mathrm{v}_{\gamma 1}$. That is, the modulation index under the fault does not present much difference for the remaining converter. However, it should be taken that the harmonic characteristics in the voltages and currents become worse when only one converter operates.

\section{Voltage on Each of the Windings by Two-Level PWM Converters}

The unique point of the proposed method is evident in the instantaneous variation of the winding voltages. To explain the voltage applied to each of the windings by the converters, the switching functions can be used to present the winding voltage in real time. The line-to-neutral voltage with respect to the switching function has been well known in the two-level converter (like Fig. 8) [10]. This earlier study is also useful for calculating the winding voltages in the DDST because the secondary windings seem to be a wye-connected inductive load under the deactivation as shown in Figs. 5 and 6. Based on the literature, the winding voltages by a two-level PWM converter can be expressed as (4) from Fig. 5 and as (5) from Fig. 6:

$$
\left\{\begin{array}{l}
\mathrm{v}_{\mathrm{a}}=\mathrm{v}_{\alpha 1}=-\mathrm{v}_{\gamma 2}=\frac{\mathrm{V}_{\mathrm{x}}}{3}\left(2 \mathrm{~S}_{\mathrm{a}}-\mathrm{S}_{\mathrm{b}}-\mathrm{S}_{\mathrm{c}}\right) \\
\mathrm{v}_{\mathrm{b}}=\mathrm{v}_{\beta 2}=-\mathrm{v}_{\alpha 2}=\frac{\mathrm{V}_{\mathrm{x}}}{3}\left(2 \mathrm{~S}_{\mathrm{b}}-\mathrm{S}_{\mathrm{a}}-\mathrm{S}_{\mathrm{c}}\right) \\
\mathrm{v}_{\mathrm{c}}=\mathrm{v}_{\gamma 1}=-\mathrm{v}_{\beta 1}=\frac{\mathrm{V}_{\mathrm{x}}}{3}\left(2 \mathrm{~S}_{\mathrm{c}}-\mathrm{S}_{\mathrm{b}}-\mathrm{S}_{\mathrm{a}}\right)
\end{array}\right.
$$




$$
\left\{\begin{array}{l}
\mathrm{v}_{\mathrm{r}}=\mathrm{v}_{\alpha 2}=-\mathrm{v}_{\gamma 1}=\frac{\mathrm{v}_{\mathrm{y}}}{3}\left(2 \mathrm{~S}_{\mathrm{r}}-\mathrm{S}_{\mathrm{s}}-\mathrm{S}_{\mathrm{t}}\right) \\
\mathrm{v}_{\mathrm{s}}=\mathrm{v}_{\beta 1}=-\mathrm{v}_{\alpha 1}=\frac{\mathrm{V}_{\mathrm{y}}}{3}\left(2 \mathrm{~S}_{\mathrm{s}}-\mathrm{S}_{\mathrm{r}}-\mathrm{S}_{\mathrm{t}}\right) \\
\mathrm{v}_{\mathrm{t}}=\mathrm{v}_{\gamma 2}=-\mathrm{v}_{\beta 2}=\frac{\mathrm{V}_{\mathrm{y}}}{3}\left(2 \mathrm{~S}_{\mathrm{t}}-\mathrm{S}_{\mathrm{r}}-\mathrm{S}_{\mathrm{s}}\right)
\end{array}\right.
$$

where $\mathrm{V}_{\mathrm{x}}$ and $\mathrm{V}_{\mathrm{y}}$ are the DC-link voltages of the abc- and rst-converters. In addition, $S_{a}$ represents the switching function for the a-phase upper switch in Fig. 8. The switching function can be 1 or 0 , which correspond to turn-on or turn-off, respectively.

By the superposition of (4) and (5), the instantaneous winding voltages can be finally derived as:

$$
\begin{aligned}
& {\left[\begin{array}{c}
\mathrm{v}_{\alpha 1} \\
\mathrm{v}_{\beta 1} \\
\mathrm{v}_{\gamma 1}
\end{array}\right]=\frac{\mathrm{V}_{\mathrm{x}}}{3}\left[\begin{array}{ccc}
2 & -1 & -1 \\
1 & 1 & -2 \\
-1 & -1 & 2
\end{array}\right]\left[\begin{array}{l}
\mathrm{S}_{\mathrm{a}} \\
\mathrm{S}_{\mathrm{b}} \\
\mathrm{S}_{\mathrm{c}}
\end{array}\right]+\frac{\mathrm{V}_{\mathrm{y}}}{3}\left[\begin{array}{ccc}
1 & -2 & 1 \\
-1 & 2 & -1 \\
-2 & 1 & 1
\end{array}\right]\left[\begin{array}{l}
\mathrm{S}_{\mathrm{r}} \\
\mathrm{S}_{\mathrm{s}} \\
\mathrm{S}_{\mathrm{t}}
\end{array}\right]} \\
& {\left[\begin{array}{c}
\mathrm{v}_{\alpha 2} \\
\mathrm{v}_{\beta 2} \\
\mathrm{v}_{\gamma 2}
\end{array}\right]=\frac{\mathrm{V}_{\mathrm{x}}}{3}\left[\begin{array}{ccc}
1 & -2 & 1 \\
-1 & 2 & -1 \\
-2 & 1 & 1
\end{array}\right]\left[\begin{array}{l}
\mathrm{S}_{\mathrm{a}} \\
\mathrm{S}_{\mathrm{b}} \\
\mathrm{S}_{\mathrm{c}}
\end{array}\right]+\frac{\mathrm{V}_{\mathrm{y}}}{3}\left[\begin{array}{ccc}
2 & -1 & -1 \\
1 & 1 & -2 \\
-1 & -1 & 2
\end{array}\right]\left[\begin{array}{l}
\mathrm{S}_{\mathrm{r}} \\
\mathrm{S}_{\mathrm{s}} \\
\mathrm{S}_{\mathrm{t}}
\end{array}\right] .}
\end{aligned}
$$

Since the switching functions can be 1 or 0 , each of the winding voltages can be varied among nine levels, which are $\pm 4 \mathrm{~V}_{\mathrm{x}} / 3, \pm 3 \mathrm{~V}_{\mathrm{x}} / 3, \pm 2 \mathrm{~V}_{\mathrm{x}} / 3, \pm \mathrm{V}_{\mathrm{x}} / 3$, and 0 when $\mathrm{V}_{\mathrm{y}}$ is equal to $\mathrm{V}_{\mathrm{x}}$. That is, the winding voltages can be synthesized with a combination of the nine voltage levels in the DDST. This is a significant improvement in the proposed method since only three levels $\left( \pm \mathrm{V}_{\mathrm{x}}, 0\right)$ are possible for the conventional method in Fig. 1. The number of voltage levels in the DDST is comparable to that of the winding voltage driven by two three-level converters.

\section{EXPERIMENTAL RESULTS}

As discussed in the previous section, the voltage levels applied to the transformer windings can be increased by up to nine in the DDST even if the fundamental voltage reference is identical. Just the simple wiring modification, shown in Fig. 2, leads to this novel improvement without any penalty in terms of winding factor or winding current. Moreover, because of the reduced switching ripple in the current, thanks to the increased voltage levels on each winding, the copper and iron losses are decreased significantly.

The effectiveness of the proposed method is examined in the small-scale PCS shown in Fig. 9. The converters were connected to a $220 \mathrm{~V} / 110 \mathrm{~V}$ transformer whose power rating is 12 kVA (3kVA per three-phase winding.) From the test measurements on the transformer, the inductive impedance was 0.037 per unit $(\mathrm{pu})$ and the resistive impedance was $0.028 \mathrm{pu}$. Because the $220 \mathrm{~V}$-grid connected to the transformer was generated by an AC programmable source, the primary voltage can be regarded as an ideal voltage at $60 \mathrm{~Hz}$. The DC-link voltage for each converter was set to $210 \mathrm{~V}$. This prototype system is only for checking the feasibility of the proposed

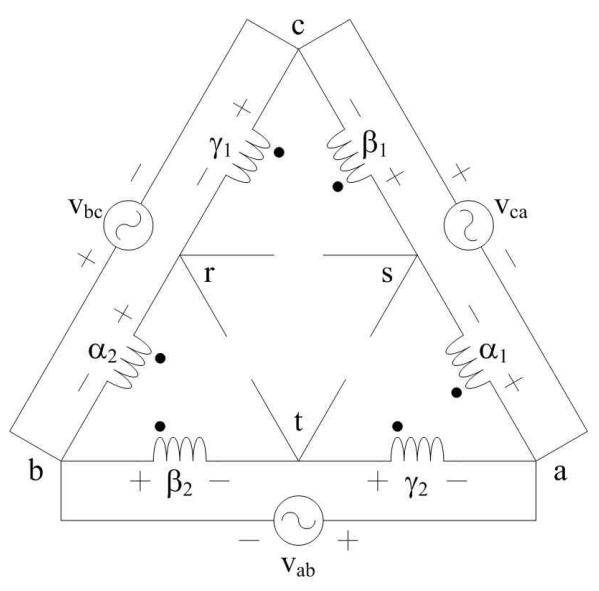

Fig. 7. Equivalent circuit when rst-converter is tripped by a fault.

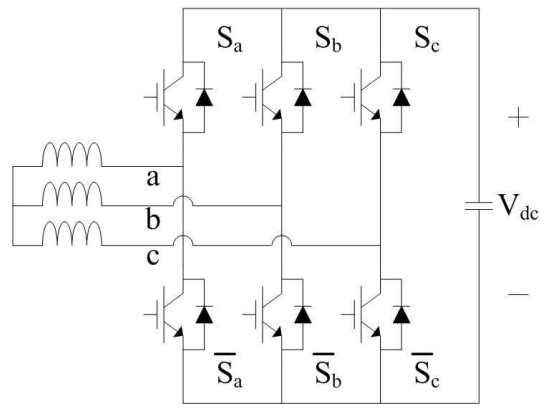

Fig. 8. Two-level converter connected to inductive load.

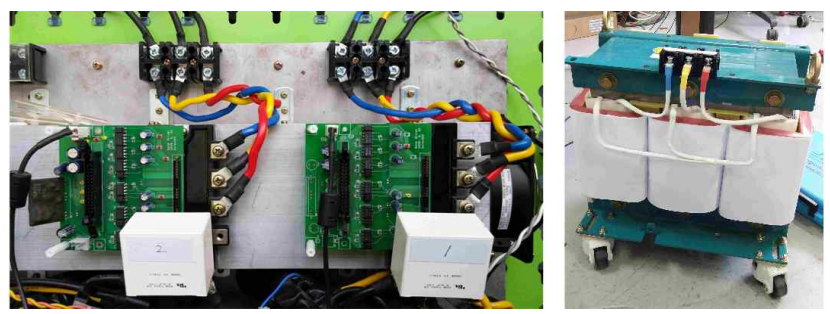

Fig. 9. Small-scale test PCS: converter and transformer.

method. To be used in industrial applications, optimization of the overall system would be necessary.

In practice, four converters have been used to further enhance the interleaving effect at the primary side as shown in Fig. 10. The carrier frequencies of the four converters are identical at $2.5 \mathrm{kHz}$, and the carriers were shifted by $90^{\circ}$ with respect to each other. Given that the carriers showing a phase difference of $180^{\circ}$ are paired for the interleaving, it can be noticed that the prototype PCS consists of two subsystems. The pair of converters $\left(\mathrm{con}_{1}\right.$ and $\left.\mathrm{con}_{2}\right)$ shown in Fig. 10, is detailed in its operation when the wiring method is changed. By modifying the wiring in the same hardware, both of the topologies shown in Figs. 1 and 2 have been tested. As an example, the following experimental results were obtained when the converters supplied about $70 \%$ of the rated power to the grid.

As emphasized earlier, the proposed method presents different voltage waveforms in the transformer windings. Fig. 11 shows the winding voltages applied at $\alpha_{1}$ and $\alpha_{2}$ (See Fig. 


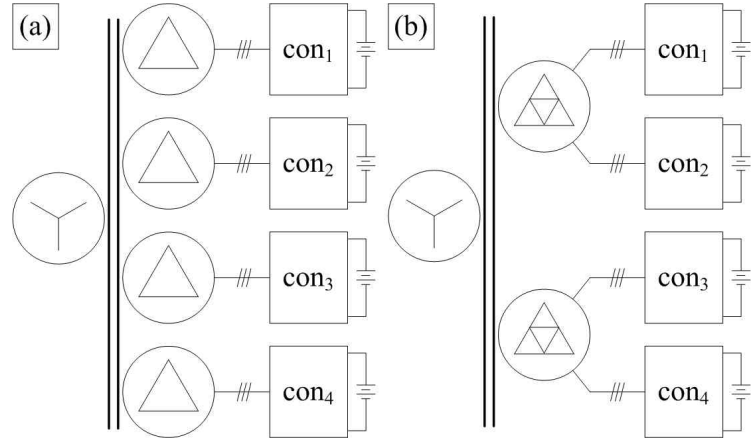

Fig. 10. Block diagrams for converter connection: (a) conventional method, (b) proposed method.

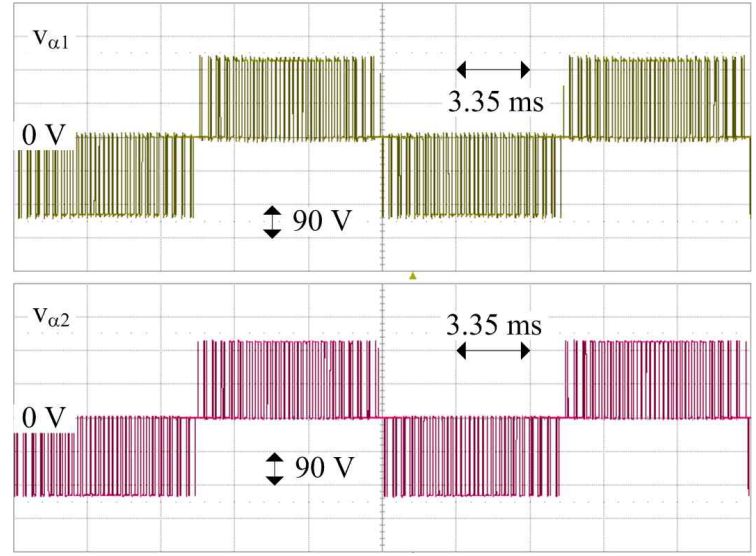

Fig. 11. Voltages on $\alpha_{1}$ and $\alpha_{2}$ in the conventional method.

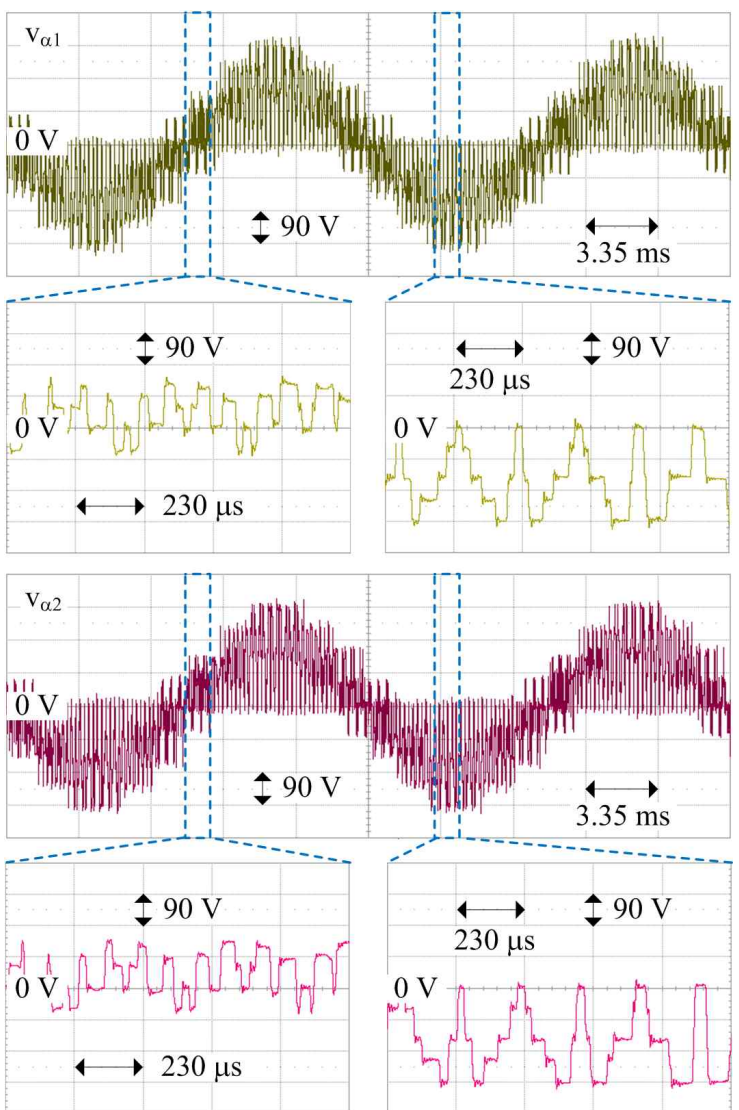

Fig. 12. Voltages on $\alpha_{1}$ and $\alpha_{2}$ in the proposed method.

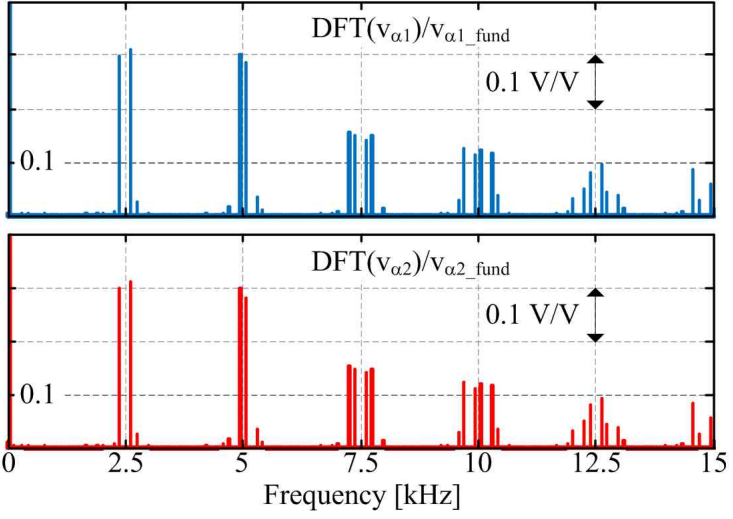

Fig. 13. Frequency spectrum on winding voltages in the conventional method.

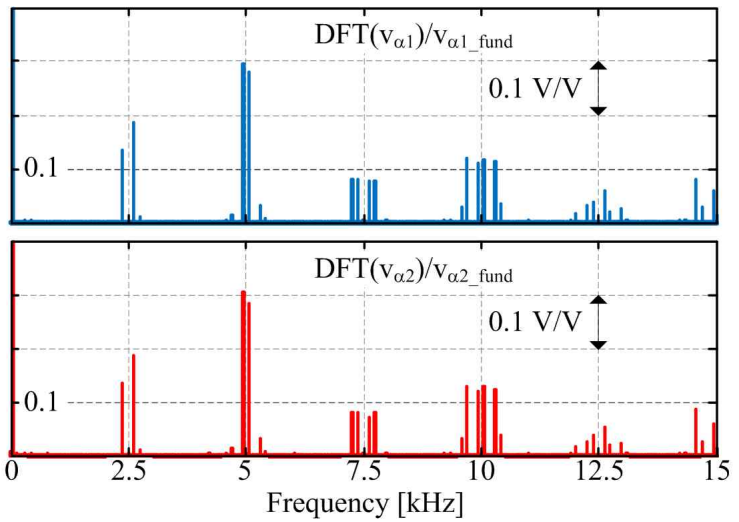

Fig. 14. Frequency spectrum on winding voltages in the proposed method.

1) when the wirings are assembled according to the conventional method. As expected, voltage variations occur among the three voltage levels. On the other hand, under the same load conditions, the number of voltage levels is increased in the DDST as shown in Fig. 12. In the enlarged plot, four levels are shown for the negative voltage range. The positive voltage range is symmetric. The voltage waveforms in the DDST more look like sine-waves. This point is quantitatively corroborated with the frequency spectrums shown in Figs. 13 and 14 , where the fundamental voltages are about $159 \mathrm{~V}$. In particular, when compared to the conventional method, the two large sideband harmonics at the switching frequency in the DDST can be mitigated by $54.9 \%$ and $39.6 \%$, respectively. With respect to the Total Harmonic Distortion (THD), it is $61.6 \%$ in the DDST while it is $81.0 \%$ in the conventional method.

The harmonics in the output voltages are directly reflected into the output currents. Ripples in the currents rather than the voltages are the main concern in grid applications [11]. By virtue of the carrier interleaving, which can be confirmed with the phase-shifted voltage outputs in Figs. 11 and 12, the current ripples at the primary side, which are contained in $i_{\alpha p}$ (Fig. 1), can be adequately suppressed in the conventional method as shown in Fig. 15. In terms of $i_{\alpha p}$, which is the grid current, the similar aspects are observed in the DDST as presented in Fig. 


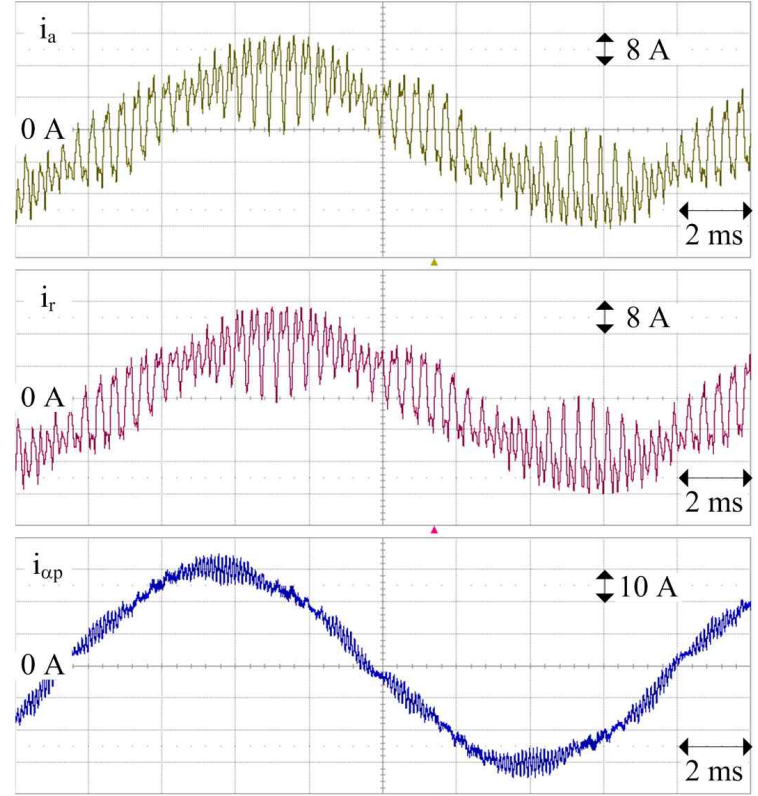

Fig. 15. Currents of grid and converters in the conventional method.

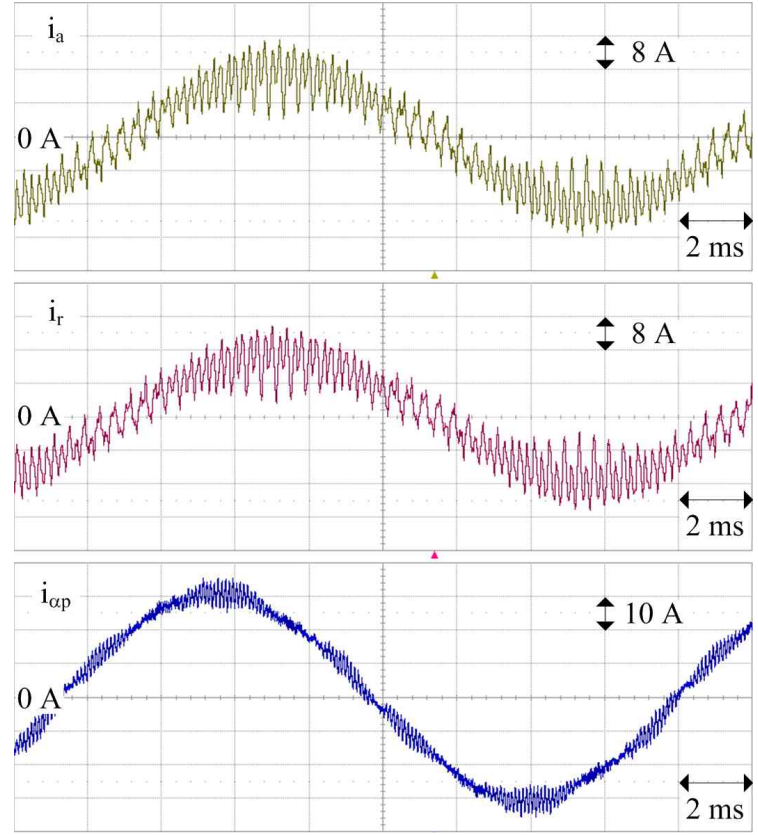

Fig. 16. Currents of grid and converters in the proposed method.

16. Namely, the THDs of the grid currents in both the conventional and the proposed methods were $8.50 \%$ and $8.08 \%$, respectively. These values seem to be large when considering the international grid THD regulation limit [11]. However, since the inductive impedance of the test transformer was relatively small $(0.0368 \mathrm{pu})$, this sort of THD is expected to be improved with the optimization through the transformer design and by increasing switching frequency.

The distinction between the topologies becomes obvious when attention is paid to the converter-side currents $\left(i_{a}\right.$ and $i_{r}$ in Figs. 1 and 2.) In the DDST, because the carrier interleaving directly affects each of the winding voltages, the current ripples

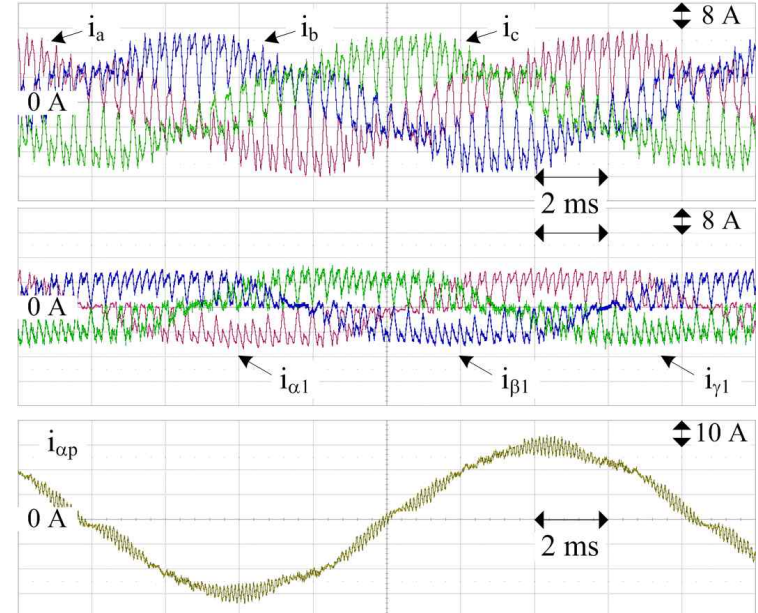

Fig. 17. Three-phase currents of converter $\left(i_{a}, i_{b}, i_{c}\right.$. $)$ and transformer winding $\left(i_{\alpha 1}, i_{\beta 1}, i_{\gamma 1}\right)$, and A-phase grid current in the conventional method.

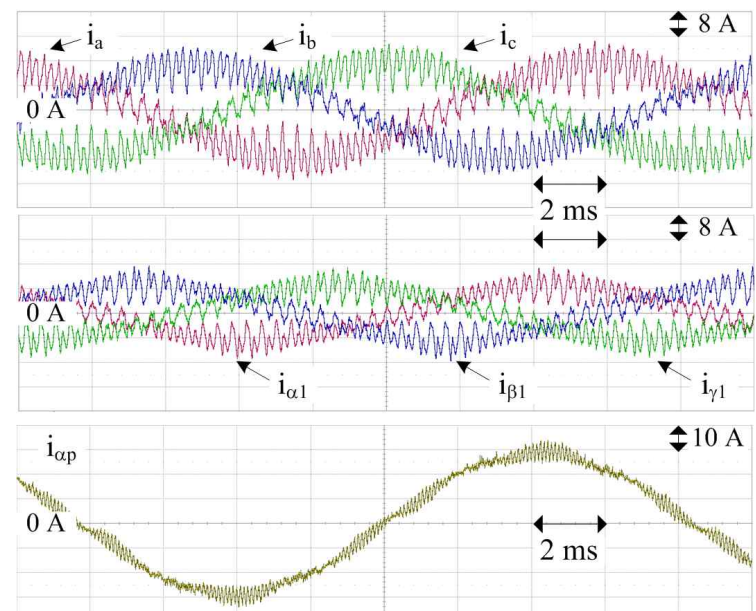

Fig. 18. Three-phase currents of converter $\left(i_{a}, i_{b}, i_{c}.\right)$ and transformer winding $\left(i_{\alpha 1}, i_{\beta 1}, i_{\gamma 1}\right)$, and A-phase grid current in the proposed method.

can be mitigated at the converter side. The ripples around the peak current can be reduced by about $30 \%$. In addition, when compared with Fig. 15, the root mean square (RMS) and peak currents in Fig. 16 are decreased by $5.8 \%$ and $2.9 \%$, respectively. This means that the conduction and switching losses of the PWM converter are reduced and that the lower current rating can be allowed for the switches in the converters depending on circumstances. When it comes to the THD of the converter currents, it can be decreased from $49.2 \%$ to $33.5 \%$ by the proposed method.

The operation of the transformer can be understood with Figs. 17 and 18. In Fig. 17 by the conventional method, because the delta winding is connected to one converter as shown in Fig. 1, the winding currents $\left(i_{\alpha 1}, i_{\beta 1}, i_{\gamma 1}\right)$ at the fundamental frequency present the differences of $1 / \sqrt{3}$ in magnitude and $30^{\circ}$ in phase to the converter currents $\left(i_{a}, i_{b}, i_{c}\right.$. $)$ The situation is identical in the DDST even though the wiring method is different. This can be confirmed from Fig. 18. 


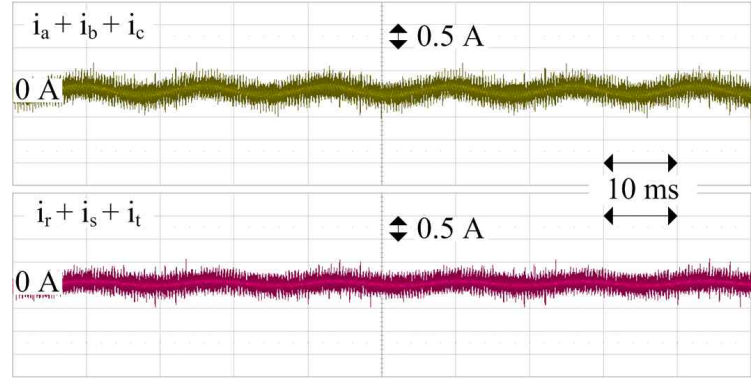

Fig. 19. DC currents injected into transformer in DDST.

From a comparison of Fig. 17 and Fig. 18, it can be shown that the current ripples at the secondary side $\left(i_{\alpha 1}, i_{\beta 1}, i_{\gamma 1}, i_{a}, i_{b}, i_{c}\right)$ can be evidently mitigated by the proposed method.

In addition, the sum of the three-phase currents in each of the converters is shown in Fig. 19 to check whether any DC current is injected into the transformer or not. As shown in the figure, it is not a problem to ignore the DC current injection in the DDST.

\section{CONCLUSIONS}

A double delta sourced transformer has been proposed in this paper. When converters are connected to the grid through a multi-winding transformer, the proposed wiring method can reduce the current ripples in converters with carrier interleaving because the number of voltage levels applied to the windings is increased conspicuously. In other words, on the basis of the conventional two-level converters, multi-level voltage outputs can be generated by the proposed method. How the converter voltages are applied to the transformer windings has been explained by the switching function of each of the PWM converters. Since better harmonic properties can be achieved by a simple modification of the wirings of conventional hardware, the proposed method is expected to have a critical advantage in grid applications where transformers are used.

\section{REFERENCES}

[1] B. P. Roberts and C. Sandberg, "The role of energy storage in development of smart grids," in Proc. of IEEE, Vol. 99, No. 6, pp.1139-1144, Jun. 2011.

[2] T. H. Nguyen and D.-C. Lee, "Ride-through technique for PMSG wind turbines using energy storage systems," Journal of Power Electronics, Vol. 10, No. 6, pp. 733-738, Nov. 2010.

[3] D.-H. Jang, and S.-K. Han, "Low cost high power density photovoltaic power conditioning system with an energy storage system," Journal of Power Electronics, Vol. 12, No. 3, pp. 487-494, May 2010.

[4] K. Vu, R. Masiello, and R. Fioravanti, "Benefits of fast-response storage devices for system regulation in ISO markets," Power \& Energy Society General Meeting, IEEE, pp. 1-8, 2009.

[5] DOE Electricity Advisory Committee, Bottling Electricity: Storage as a Strategic Tool for Managing Variability and Capacity Concerns in the Modern Grid, 2008, [Online]. Available:http://energy.gov/sites/prod/files/oeprod/Docume ntsandMedia/final-energy-storage 12-16-08.pdf
[6] B. Dunn, H. Kamath, and J.-M. Tarascon, "Electrical energy storage for the grid: A battery of choices," Science, Vol. 334, No. 18, pp. 928-935, Nov. 2011.

[7] M. Liserre, F. Blaabjerg, and S. Hansen, "Design and control of an LCL-filter-based three-phase active rectifier," IEEE Trans. Ind. Appl., Vol. 41, No. 5, pp. 1281-1291, Sep./Oct. 2005.

[8] K. Jalili and S. Bernet, "Design of LCL filters of active-front-end two-level voltage-source converters," IEEE Trans. Ind. Electron., Vol. 56, No. 5, pp. 1674-1689, May 2009.

[9] J. S. S. Prasad, and G. Narayanan, "Minimization of grid current distortion in parallel-connected converters through carrier interleaving," IEEE Trans. Ind. Electron., Vol. 61, No. 1, pp. 76-91, Jan. 2014.

[10] D. G. Holmes and T. A. Lipo, "Switching function representation of three-phase converters," in Pulse Width Modulation for Power Converters: principles and practice, John Wiley \& Sons, Inc., Chap. 1-3, pp. 14-16, 2003.

[11] IEEE Standard for Interconnecting Distributed Resources With Electric Power Systems, IEEE Std. 1547, 2003.

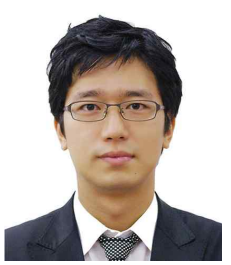

Yongsoon Park received his B.S. and M.S. degrees in Electrical Engineering from Seoul National University, Seoul, Korea, in 2008 and 2010, respectively, where he is currently working toward his Ph.D. degree. His current research interests include power conversion circuits and sensorless motor drives.

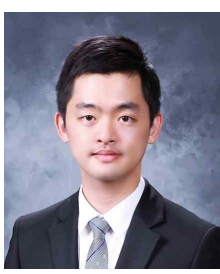

Sungjae Ohn was born in Seoul, Korea, in 1988. He received his B.S. degree in Electrical Engineering from Seoul National University, Seoul, Korea, in 2013, where he is currently working toward his M.S. degree. His current research interests include power electronics, multi-winding transformers, and electronic power distribution systems.

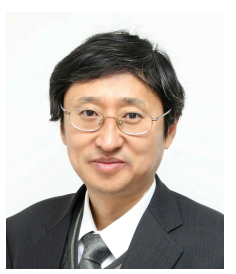

Seung-Ki Sul received his B.S., M.S., and $\mathrm{Ph} . \mathrm{D}$. degrees in Electrical Engineering from Seoul National University, Seoul, Korea, in 1980, 1983, and 1986, respectively. From 1986 to 1988, he was an Associate Researcher in the Department of Electrical and Computer Engineering, University of Wisconsin-Madison, Madison, WI, U.S.A. From 1988 to 1990, he was a Principal Research Engineer with Gold-Star Industrial Systems Co., Korea. Since 1991, he has been a member of the faculty in the School of Electrical Engineering, Seoul National University, where he is currently a Full Professor. Since 2000, he has been an IEEE Fellow. From 2003 to 2004, he was a Research Director and an Acting Consultant for Yaskawa Electric Co., Japan. From 2005 to 2007, he was the Vice Dean of the Engineering College of Seoul National University. In addition, from 2008 to 2011, he was the President of the Electrical Engineering Science Research Institute funded by the Korean Government. He has published over 120 reviewed journal papers, mainly IEEE transactions. He was Technical Chair of the IEEE PESC2006 conference and General Chair of the IEEE ECCE-Asia 2011. He is currently Editor-in-Chief of the Journal of Power Electronics, which is a SCIE registered journal, published by the Korean Power Electronics Institute, Seoul, Korea. His current research interests include power electronic control of electrical machines, electric/hybrid vehicle and ship drives, and power-converter circuits for renewal energy sources. 